\title{
Evaluation of User Contribution Value in the Virtual Brand Community
}

\author{
Zhihong Li, Yanhong Zhou* \\ Department of Business Administration, South China University of Technology, Guangzhou, China
}

Email address:

bmzhhli@scut.edu.cn (Zhihong Li), 80435863@qq.com (Yanhong Zhou)

${ }^{*}$ Corresponding author

\section{To cite this article:}

Zhihong Li, Yanhong Zhou. Evaluation of User Contribution Value in the Virtual Brand Community. Journal of World Economic Research. Vol. 6, No. 4, 2017, pp. 46-53. doi: 10.11648/j.jwer.20170604.11

Received: April 24, 2017; Accepted: May 3, 2017; Published: July 5, 2017

\begin{abstract}
Virtual brand community has become the platform for users to obtain product knowledge, share experience and interact with other members. However, integrative research that investigates the process and possible contribution of these behaviors in the virtual brand community remains limited. Based on an extensive review of literature on user behavior, we divide user contribution value into user-contributed content value and user interaction value. Then we use weighted knowledge super-network model and weighted knowledge network model to estimate the value of users. We test our model with a dataset from a Chinese virtual brand community, Millet forum. According to the different features of users, we build a two-dimensional matrix of user contribution value. Our model and findings provide important implications for better understand and manage users in the virtual brand community.
\end{abstract}

Keywords: Virtual Brand Community, User Behavior, User Contribution Value, Knowledge Network, Weighted Knowledge Super-Network

\section{Introduction}

With the rapid development of Internet, the way of getting information from the traditional face-to-face communication gradually transformed into online communication $[1,26]$. According to the report of China Internet development CNNIC (China Internet Network Information Center), as of December 2015, the Internet users of China has reached 688 million, Internet penetration rate reached $50.3 \%$; the scale of mobile phone users reached 620 million, accounting for up to $90.1 \%$, the wireless network coverage has improved significantly, Wi-Fi usage of Internet users reached $91.8 \%$ [33].

The first social networking site (Six Degrees) was launched in 1997, based on the idea that everybody is linked with others through six degrees of separation, and initially referred to as the "small world problem" $[4,38]$. In recent years, more virtual community was established. Users join a virtual community mainly for information collection, knowledge transfer, social connection and social identity [7, 12]. Users' behaviors in the virtual brand community include browse the forums, publish posts and interact with other members of the community [34]. At the same time, they are also create value to the community, which is an important resource of knowledge innovation and product marketing.

Despite its importance, integrative research that investigates the process and possible contribution of user behavior in virtual brand community remains limited $[14,16$, 20,23]. Our research makes several contributions. Our study contributes to category on user contribution value in virtual brand community. Then, we empirically analyze the value of user behavior, we use weighted knowledge super-network model and weighted knowledge network model to estimate their contribution. From the platform owner's perspective, our findings shed light on thevalue of user behavior for virtual platforms.

The remainder of this paper is organized as follows. Section 2 reviews the related literature. In Section 3, we present the empirical model, namely weighted knowledge 
super-network model WKSN to measure user-contributed content value and P-P weighted network model to measure user interaction value. We present the main empirical results in Section 4. Finally, in Section 5, we discuss the implications of our study and conclude the paper.

\section{Theoretical Background}

\subsection{User Contribution Value}

Most marketing scholars suggest that customer value will become more important in the future competition of resources and innovation [41]. With the rapid development of information technology, it is even more necessary for enterprises to scientifically manage their users [10]. The behavior of users is an important source of knowledge innovation and product marketing, which can help enterprises effectively allocate resources and provide personalized services $[8,18]$.

Parmentier et al. (2014) show importance of interaction among users, which can generate knowledge innovation [26]. Robert et al. (2002) show that enterprises with higher user identity can create value and increase profits [27], Kotler et al. (2001) develop a conceptual model that user demand and user contribution constitutes user value. They suggest that user demand value is the ability for enterprises to meet customer's needs, while user contribution value is the ability for users to help enterprises gain profits after purchase its products or services [49]. In this paper, we study the user contribution value from the perspective of enterprise.

\subsection{User Contribution Value of Virtual Brand Community}

Virtual brand community is a combination of brand community and virtual community in the internet environment. Boorstin et al. (1973) first propose the concept of consumption community, which becomes the prototype of brand community. It has a very important role in the field of marketing. Kozinets et al. (2002) think virtual brand community means community members can exchange product information and brand experiences based on brand forum, blog, BBS and other platforms [17]. Jin (2007) think virtual brand community is community that members communicate online with other members surrounding brand knowledge [15]. Virtual brand community has three characteristics. First, it is produced from Internet technology, without time and geographical space limit. Second, it is built on the interest of users and experience in product. Third, the purpose of establishing virtual brand community is to maintain companies' image and deliver product information.

By browsing the forums, publish posts and interacting with members of the community, users can obtain product information, transfer knowledge and gain social identity. For enterprises, they can excavate product innovation from the posts, find user needs about products, then provide more personalized and specialization service, which forms user-contributed content value. Besides, interaction among members indirectly spread positive word of mouth of product, which forms user interaction value.

\subsection{Knowledge Network}

In the era of knowledge economy, knowledge is considered to be the most important strategic resource. Maximize the value of the organizational knowledge is the key element to enhance core competitiveness of organizations. Knowledge network provides a tool for the study of knowledge generation, sharing and recreation [22, 25].

Research on knowledge network involves structures of network, types of network, evolution of network and management of network [27]. Zhao (2007) shows knowledge network can be divided into three categories: self-knowledge network, organizational knowledge network and social knowledge network [47]. From the perspective of different relationship of knowledge network, Wang et al. (2007) divide it into three categories: interpersonal networks, resource network and technical network [39]. Based on the node type of knowledge network, Xi et al. (2005, 2007, 2009) divide it into three categories: K-K network (network between different knowledge points); P-P network (network between different members); M-M Network (network between different material carriers) $[42,43,44]$. In our research, we use weighted knowledge super-network and weighted P-P knowledge network to study user-contributed content value and user interaction value, respectively.

\subsection{Knowledge Super-Network}

Although the definition of super-network is diverse, its main characteristics include: large-scale, complex connection and heterogeneous network nodes [9]. Super-network is constituted by mutually connecting with different networks. That is, different from the traditional directed or undirected networks, one edge can connect more than two nodes in super-networks [2, 19].

Super-network model is widely used in supply chain and transportation industry, Berge (1973) first propose the concept of hypergraph [3]. Nagurney et al. (2002) build a super-network model contains market, manufacturers and vendors elements, it solves the interactive problem between logistic network, financial network and information network [24]. Some scholars also use super-network as a means of optimize individual travel route network and balance the overall transportation network [42]. Xi et al. (2007) propose weighted knowledge network (WKN) and weighted knowledge super-network (WKSN) to study the relationship between different knowledge carriers.

\section{The Model}

Our objective is to estimate user contribution value in the virtual brand community. We have aggregate data for the number of users and posts in a period of time, when users publish content for knowledge sharing in a virtual brand 
community. To account for these behaviors, we build knowledge super-network model and knowledge network model that capture user behavior value as suggested by Xi et al. (2007). This model allows us to overcome the interactive problem among different networks and accommodate the possibility of interaction effects. Further, there can be heterogeneity in the degree of importance for different knowledge. To capture this, we consider weight coefficient based on the literature of knowledge network [42, 43]. Users' behaviors in virtual brand community include knowledge sharing, interest discovering, interactive learning and relationship maintaining, which forms user-contributed content value and user interaction value. This approach allows us to evaluate the two kinds of value while accounting for the importance of knowledge. Similar models have been used to study user knowledge innovation in public community $[18,44]$.

\subsection{Weighted Knowledge Super-Network Model}

By publishing content and communicating with other members, users formulate the knowledge network and interaction relationship of virtual brand community. Therefore, the virtual brand community contains two main types of knowledge networks: K-K knowledge network (network between different knowledge points) and P-P knowledge network (network between different members). Besides, members with specific knowledge points constitute user-contributed content value. However, the traditional network can not reflect this relationship, so we use weighted knowledge super-network (WKSN) capture it.

Take members and knowledge points as nodes, and take the relationship between users and knowledge points as edges, we build weighted knowledge super-network model WKSN to estimate user-contributed content value in virtual brand community, i.e.,

$$
\mathrm{WKSN}=\left(\mathrm{K}, \mathrm{P}, E_{k-k}, E_{p-p}, E_{p-k}, \mathrm{Q}\left(k_{j}\right), W\left(E_{k-k}\right), Q\left(E_{p-k}\right)\right)
$$

Where $\mathrm{K}$ represents knowledge points of the community, $\mathrm{P}$ represents member of the community. $\mathrm{E}_{\mathrm{k}-\mathrm{k}}=\left\{\left(\mathrm{k}_{\mathrm{i}}, \mathrm{k}_{\mathrm{j}}\right) \mid \alpha\left(\mathrm{k}_{\mathrm{i}}, \mathrm{k}_{\mathrm{j}}\right)=1\right\}$ is the set of edges among knowledge nodes, $\alpha\left(\mathrm{k}_{\mathrm{i}}, \mathrm{k}_{\mathrm{j}}\right)=1$ if there exists a link between knowledge points $\mathrm{i}$ and $\mathrm{j}$, means co-occurrence for knowledge points $\mathrm{i}$ and $\mathrm{j}$ in one post. $\mathrm{E}_{\mathrm{p}-\mathrm{p}}=\left\{\left(\mathrm{p}_{\mathrm{i}}, \mathrm{p}_{\mathrm{j}}\right) \mid \beta\left(\mathrm{p}_{\mathrm{i}}, \mathrm{p}_{\mathrm{j}}\right)=1\right\}$ is the set of edges among user nodes, $\beta\left(p_{i}, p_{j}\right)=1$ if there exists a link between user $i$ and $\mathrm{j}$, means interaction between user $\mathrm{i}$ and $\mathrm{j}$. $\mathrm{E}_{\mathrm{p}-\mathrm{k}}=$ $\left\{\left(\mathrm{p}_{\mathrm{i}}, \mathrm{k}_{\mathrm{j}}\right) \mid \gamma\left(\mathrm{p}_{\mathrm{i}}, \mathrm{k}_{\mathrm{j}}\right)=1\right\}$ is the set of edges between user $\mathrm{i}$ and its knowledge point $\mathrm{j}, \gamma\left(\mathrm{p}_{\mathrm{i}}, \mathrm{k}_{\mathrm{j}}\right)=1$ if knowledge point $\mathrm{j}$ belongs to user $\mathrm{i}$.

To capture the heterogeneity in the degree of importance for different knowledge points and members, we also consider weight coefficient in our model. Where $\mathrm{Q}(\mathrm{K})=$ $\left\{\mathrm{q}\left(k_{j}\right)\right\}$ represents the weight set of knowledge points stock; $\mathrm{q}\left(k_{j}\right)$ represents the stock of knowledge points $k_{j}$ in all users, $Q\left(E_{p-k}\right)=\left\{q\left(p_{i}, k_{j}\right) \mid \varnothing\left(p_{i}, k_{j}\right)=1\right\}$ is the weight set of each edge in set $E_{p-k}$, the value of weight indicates the frequency of knowledge point $\mathrm{j}$ in a post for user $\mathrm{i}$. $\mathrm{W}\left(\mathrm{E}_{\mathrm{k}-\mathrm{k}}\right)=\left\{\mathrm{w}\left(\mathrm{k}_{\mathrm{i}}, \mathrm{k}_{\mathrm{j}}\right) \mid \varepsilon\left(\mathrm{k}_{\mathrm{i}}, \mathrm{k}_{\mathrm{j}}\right)=1\right\}$ is the weight set of set $E_{k-k}$, indicates the number of co-occurrence of knowledge points in a post.

\subsection{Weighted Knowledge Network Model}

By posting and replying the posts in the virtual brand community, user interaction relationships are formed. What's more, the relationships between members are weak ties, based on brand loyalty and same interests about brand-related information. These interaction behaviors generate user interaction value. Take members in the community as nodes, and take the interaction relationship among members as edges, we build a P-P weighted network model to measure user interaction value:

$$
G_{p}=\left(P, E_{p-p}, W\left(\mathrm{E}_{\mathrm{p}-\mathrm{p}}\right)\right)
$$

Where $\mathrm{P}$ represents the members who posts and replies in the community; $E_{p-p}=\left\{\left(p_{i}, p_{j}\right) \mid \beta\left(p_{i}, p_{j}\right)=1\right\}$ is the set of edges among the nodes of members, $\beta\left(p_{i}, p_{j}\right)=1$ if there exists a link between members $i$ and $j$, namely they have had an interaction behavior in one post.

Same as above, to capture the interaction level between members, we also consider weight coefficient in our model. Where $W\left(E_{p-p}\right)=\left\{w\left(p_{i}, p_{j}\right) \mid \varepsilon\left(p_{i}, p_{j}\right)=1\right\}$ is the weight set of set $E_{p-p}$, indicates the number of interactions between users in a post.

\section{Empirical Validation}

\subsection{Empirical Context and Data Description}

We obtained a data set from a Chinese virtual brand community, Millet forum, to evaluate user contribution value in the virtual brand community. Our data set consists of the posts and user information from October 19, 2013 to August 25, 2014, a total number of 5641 records. We delete posts whose content are empty or repeat. Consider our study is about community knowledge and users who contribute knowledge to the community, we also delete posts without reply and page views less than 400 . The final number of posts is 866 .

We use segmentation tool, NLPIR, to deal with the posts, and we adopt TF-IDF algorithm to extract keywords. First we choose the top five percent of keywords and the frequency of keywords more than five times in a post. If the length of the article is short, we choose the frequency of keywords more than two times in a post, and the number of words range at $3-5$. We finally extract 925 keywords and the total frequency is 22344 .

To analyze the interaction between community members, we also extract user information. In the original data, there are 9230 users. Users who have ever posted are 628, and users who only replied to the posts are 8602 . We define there exists a link when user i reply to post $\mathrm{j}$. 


\subsection{Evaluation of User-Contributed Content Value Based on Weighted Knowledge Super-Network}

In the virtual brand community, user-contributed content value can not measured only by the amount of posts. However, we should consider whether a post contains higher professional and technical content, or information that useful to the enterprises and others members, namely the core knowledge points. According to Pareto principle (80/20 rule), we select keywords whose frequency of occurrence are at the top $22.8 \%$ (the top 20 keywords) as core knowledge points, as shown in Figure 1.

In our model, user relationship constitutes by users who contribute to the core knowledge points. As shown in Figure 2, hollow nodes are core knowledge points, and solid nodes are users who contribute to core knowledge points. There exist three types of edges, which are relationships of reply between users, co-occurrence relationships of knowledge points in one post, relationship between users and its knowledge points, respectively.

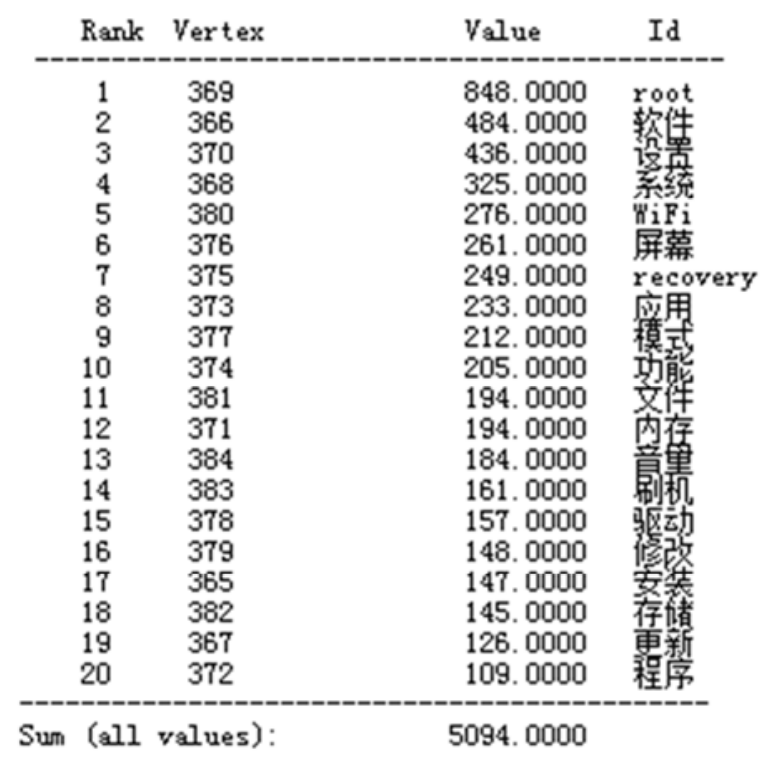

Figure 1. The frequency of top 20 keywords.

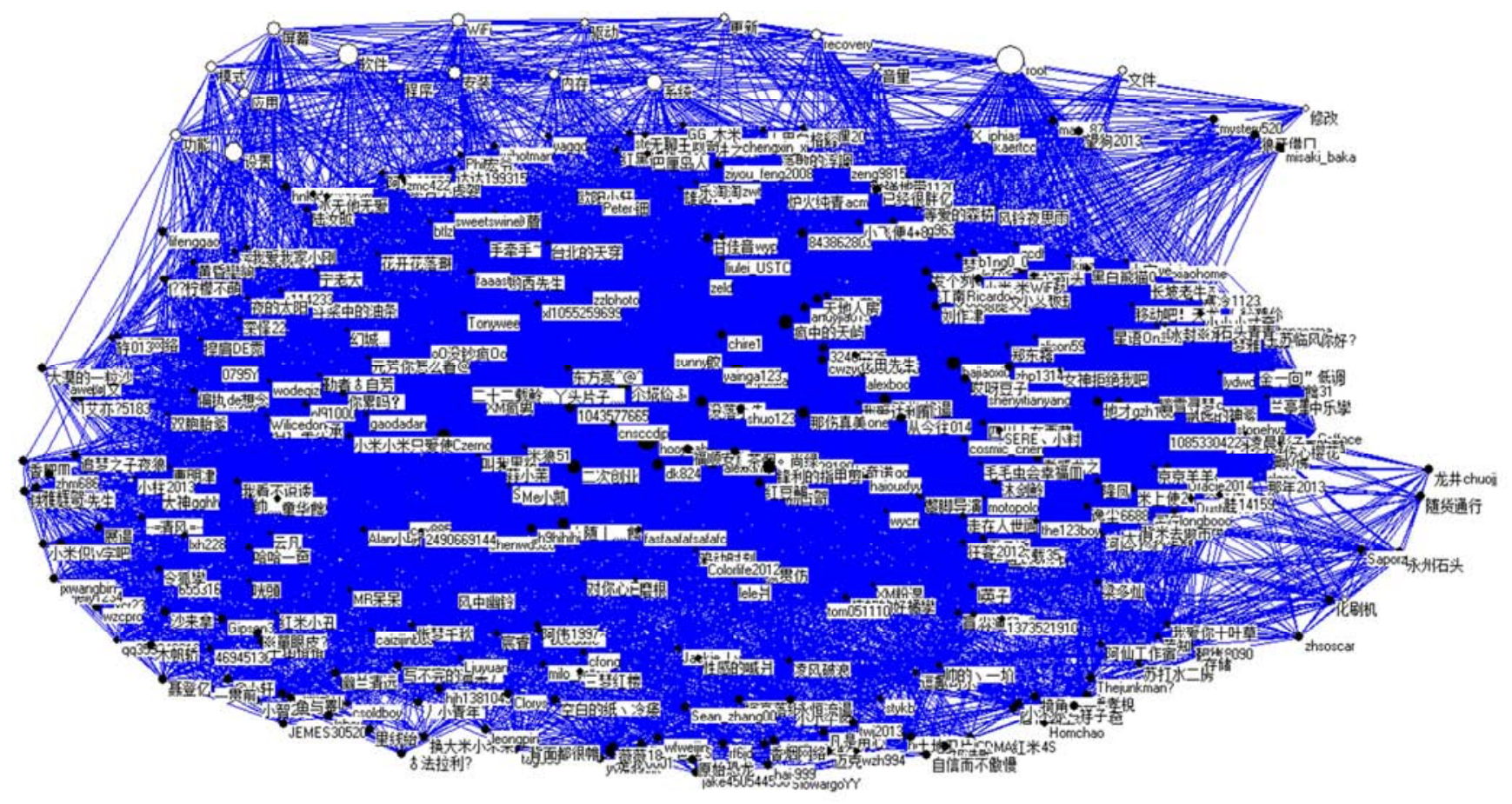

Figure 2. WKSN network of user-contributed content.

Based on WKSN model, we use Pajek tool to calculate user-contributed content value, as shown in Figure 3. We can see that contribute value of user hooyeah is 806 , which is the maximum value of all users. User 二次创业 followed, whose value is 409 , belongs to the high value user. While users like 米粉丽人, 断了的弦 520 also join the community, but their value is much smaller. By check user's information, we found that user hooyeah and user 二次创业 are members of Coldplay group in Millet forum, users in Coldplay group acquire more expertise compared to ordinary group, correspondingly, their user-contributed content value are higher. 


\begin{tabular}{|c|c|c|c|}
\hline Rank & Vertex & Value & Id \\
\hline $\begin{array}{r}1 \\
2 \\
3 \\
4 \\
5 \\
6 \\
7 \\
8 \\
9 \\
10\end{array}$ & $\begin{array}{r}33 \\
29 \\
78 \\
112 \\
11 \\
15 \\
14 \\
32 \\
16 \\
56\end{array}$ & $\begin{array}{l}806.0000 \\
409.0000 \\
339.0000 \\
310.0000 \\
289.0000 \\
281.0000 \\
263.0000 \\
262.0000 \\
251.0000 \\
243.0000\end{array}$ & 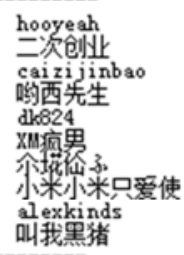 \\
\hline $\begin{array}{l}624 \\
625 \\
626 \\
627 \\
628\end{array}$ & $\begin{array}{l}550 \\
613 \\
529 \\
628 \\
534\end{array}$ & $\begin{array}{l}1.0000 \\
1.0000 \\
1.0000 \\
1.0000 \\
1.0000\end{array}$ & 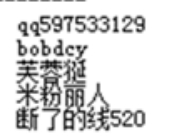 \\
\hline & & 5094. & \\
\hline
\end{tabular}

Figure 3. User-contributed Content Value operating results.

\subsection{Evaluation of User Interaction Value Based on Weighted Knowledge Network}

In the virtual brand community, mutual reply relationship among users constitutes the interaction network. Take 9230 users as nodes, and take user interaction in a same post as edges, we build a user set $\mathrm{P}$ and a user relationship set $E_{p-p}$. We also consider the interaction level between different members, measured by weighted set $W\left(\mathrm{E}_{\mathrm{p}-\mathrm{p}}\right)$, indicates that the times of interaction between members in a post. Shown in Figure 4, the numbers on edges represent interaction level among members.

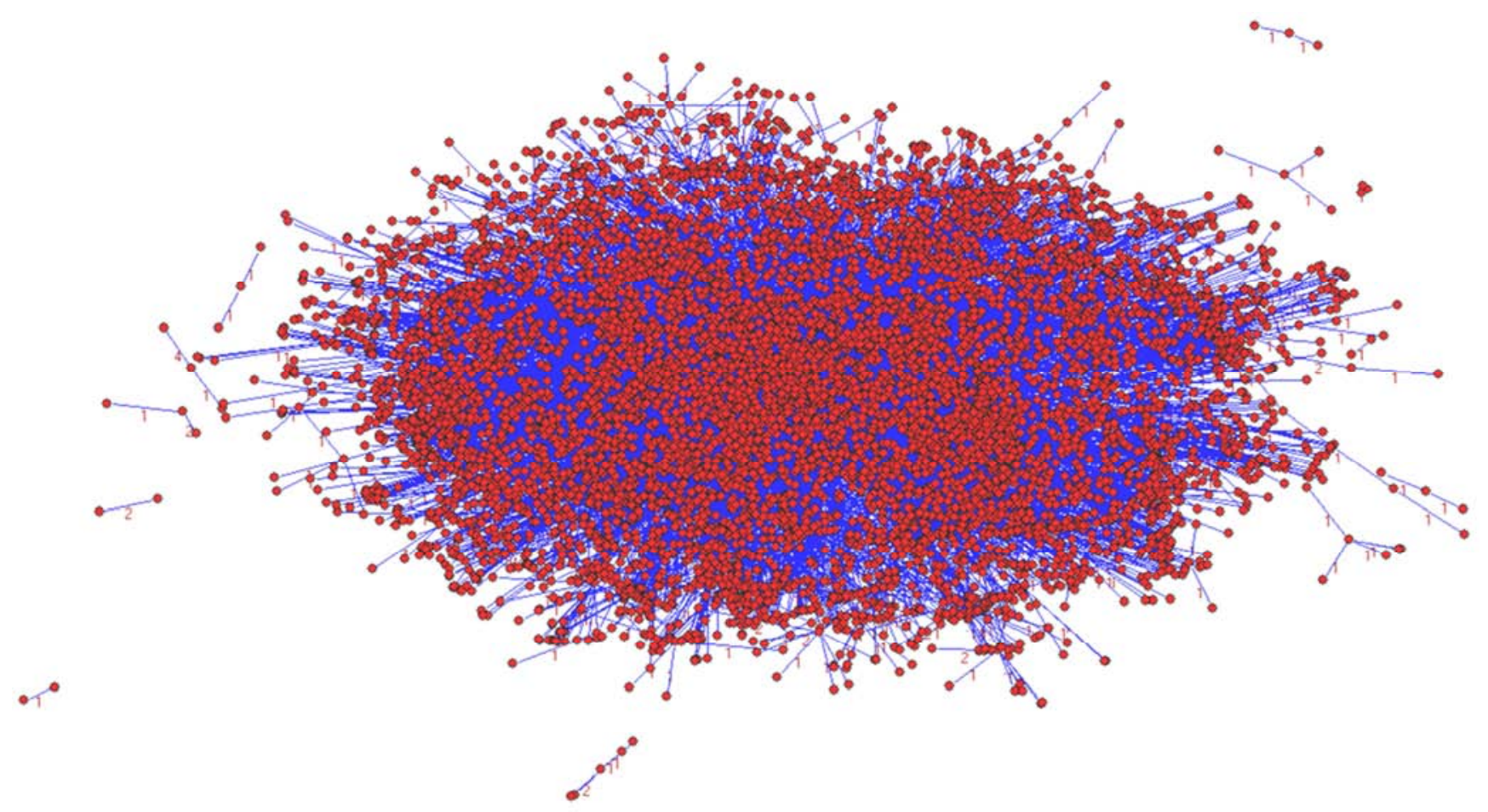

Figure 4. P-P weighted knowledge network of user interaction value.

Research on user interaction relationship is to find the influential users in virtual brand community, who have ability to diffuse information, interact with other members and conduct behaviors independently. We adopt social network analysis to evaluate these abilities, and the results are shown in Table 1.

Table 1. Ranking of user interaction value in the virtual brand community.

\begin{tabular}{|c|c|c|c|c|c|}
\hline User name & Degree Centrality & User name & Betweenness Centrality & User name & Closeness Centrality \\
\hline hooyeah & 0.0728 & hooyeah & 0.1574 & 叫我黑猪 & 0.3211 \\
\hline alekinds & 0.0393 & $\operatorname{gd} 5320$ & 0.1061 & hooyeah & 0.3208 \\
\hline 二次创业 & 0.0326 & $\mathrm{oO}$ 没钞疯 Oo & 0.0894 & $\mathrm{oO}$ 没钞疯 $\mathrm{Oo}$ & 0.3182 \\
\hline 1043577665 & 0.0289 & 叫我黑猪 & 0.0718 & $\mathrm{XM}$ 疯男 & 0.3133 \\
\hline Czerno & 0.0278 & 1043577665 & 0.0690 & $\mathrm{dk} 824$ & 0.3130 \\
\hline $\mathrm{oO}$ 没钞疯 $\mathrm{Oo}$ & 0.0263 & alekinds & 0.0674 & 二次创业 & 0.3087 \\
\hline $\mathrm{dk} 824$ & 0.0262 & Czerno & 0.0635 & 疯中的天屿 & 0.3078 \\
\hline 叫我黑猪 & 0.0228 & $\mathrm{dk} 824$ & 0.0588 & 你累吗? & 0.3071 \\
\hline 小米小米只爱使 & 0.0223 & $\mathrm{XM}$ 疯男 & 0.0541 & alekinds & 0.3061 \\
\hline$\ldots$ & $\ldots$ & $\ldots$ & $\ldots$ & $\ldots$ & $\ldots$ \\
\hline 米果酿 & 0.0001 & 米粉丽人 & 0.0000 & 岩琪 & 0.0002 \\
\hline lmy8026 & 0.0001 & Sweetswine & 0.0000 & 疯狂火吻 & 0.0002 \\
\hline 我是奶粑 & 0.0001 & 疯狂火吻 & 0.0000 & 罗永灿 & 0.0002 \\
\hline
\end{tabular}




\subsection{Cluster Analysis}

As described above, combined both user-contributed content value and user interaction value, there exists four indicators: user-contributed content value, degree centrality, betweenness centrality, closeness centrality. Take user name as a unique identification, we use K-means clustering to cluster the four variables. As shown in table 2.

Table 2. Final number of users in each cluster.

\begin{tabular}{lll}
\hline & 1 & 1.000 \\
Clustering & 2 & 13.000 \\
& 3 & 114.000 \\
Effective Values & 4 & 9102.000 \\
Missing Values & & 9230.000 \\
\hline
\end{tabular}

We can see that users in the virtual brand community are clustered into four categories: $\{1$. hooyeah $\} ;\{2$. Czerno, Alan 小明, dk824, 1043577665, oO 没钞疯 Oo, 尔埖仙 3, XM 疯男, 二次创业, 小米小米只爱使, alexkinds, 吆西先生, 叫我黑猪, caizijinbao \}; \{3. 煙鬼, 花开花落 溿, MR 呆呆, Sawalice, 茶烟。尚绿, 疯中的天屿, lwjieiuia, hnkjdxswgcxm, 鱼与罿, yuzf0001, 卓大猿 etc. $\}$; $\{4$. 疯 狂火吻, sweetswine, XDH 开忿, 我姓从 $\mathrm{i}$, 人体肌肉, cwj-elsa, 破进吚, 我似风似氿, 8.88889E+13, 为小米加 油!, neB520, richardqiang, 萌山风景 etc.\}.

We test the four variables with variance analysis. Observed in table 3 , the result is significantly, indicate that it is feasible to measure user contribution value with these four indicators.

Table 3. Variance analysis.

\begin{tabular}{|c|c|c|c|c|c|c|}
\hline & \multicolumn{2}{|l|}{ Cluster } & \multicolumn{2}{|l|}{ Error } & \multirow{2}{*}{$\mathbf{F}$} & \multirow{2}{*}{ Sig. } \\
\hline & Mean Square & df & Mean Square & df & & \\
\hline degree centrality closeness centrality & .005 & 3 & .000 & 9227 & 6126.041 & .000 \\
\hline betweenness centrality user-contributed & .097 & 3 & .001 & 9227 & 67.525 & .000 \\
\hline content value & .023 & 3 & .000 & 9227 & 4930.418 & .000 \\
\hline contributed content value & 669160.313 & 3 & 27.926 & 9227 & 23961.549 & .000 \\
\hline
\end{tabular}

We extract the features for each category of users, and build a two-dimensional user matrix. The horizontal axis is user-contributed content value and the vertical axis is user interaction value. According to their different features, we divided users into four categories, as shown in figure 5.

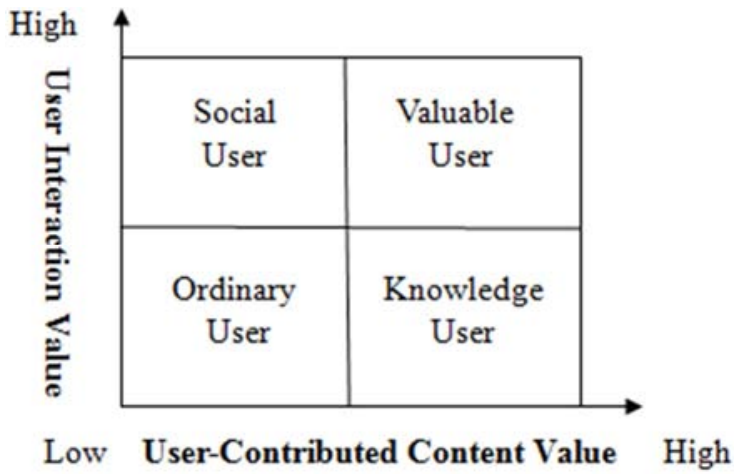

Figure 5. Two-dimensional user matrix.

Valuable users (first type of users), they have the greatest value to the community, but they number is very few. They usually have professional product knowledge, higher brand loyalty, and enjoy communicating with others members. They are the most valuable users in the virtual brand community.

Knowledge users (second type of users), they have rich experience in product, and willing to contribute their knowledge in the community. But their interaction with other members is relatively rare. The percentage of these users is not high. They are important to the enterprise, which are important source for product innovation.

Social users (third type of users), these users actively interact with other members, they have higher "power" in the community, and can affect other members. But they have limited knowledge, so their user-contributed content value is smaller. They play an important role in marketing and product promotion.

Ordinary users (fourth type of users), these users take up the largest proportion in the community. They have limited knowledge, rarely interact with other members or share experience. But they depend on the community for product information. Besides, if being motivated, they will be converted to other types of users.

\section{Conclusion}

In this paper, we investigate the behavior of users in the virtual brand community. Based on an extensive review of literature on user behavior, we divide user contribution value into user-contributed content value and user interaction value. Then we use weighted knowledge super-network model and weighted knowledge network model to estimate it. According to the different features of users, we build a two-dimensional user matrix. Our model and findings provide important implications for managing users in the virtual brand community.

Our study makes several contributions and has implications for virtual brand platforms. Attracting customers and spreading brand knowledge has become a critical part of platforms' strategies. For valuable users, brand platforms can give them priority to new products and promote their rank in the community. For knowledge users, brand platforms can encourage them to participate in the process of product innovation. For social users, brand platforms can induce them to organize product promotion. For ordinary users, platforms can create a fair, friendly, innovative, and trust community environment, enhance their behavioral expectation and brand 
dependence.

Our study is not without limitations. We only use the data of one community to validate our evaluation models. However, there may be heterogeneity for different communities. Besides, we use core knowledge points of users to evaluate user-contributed content value, may lead to some of key knowledge lost. At last, in this paper, we do not consider the user's personal characteristics such as gender, age, education level, geographic location etc., which may also have an impact on user contribution value. Future research could improve these aspects.

\section{Acknowledgements}

The work described in this paper was substantially supported by 3 grants from the Research Grant Council of South China University of Technology, China (National Natural Science Foundation Project 71571073, Natural science fund project in Guangdong province 2014A030313243 and Philosophy and Social Science $12^{\text {th }}$ Five-Year Plan project in Guangdong province GD14CGL09).

\section{References}

[1] Algesheimer, R., U. M. Dholakia, and A. Herrmann, The Social Influence of Brand Community: Evidence from European Car Clubs. Journal of Marketing, 2005. 69 (4): p. págs. 19-34.

[2] Arthur, G., Net gain: expanding market through virtual communities. 1997.

[3] Bagozzi, R. P. and U. M. Dholakia, Antecedents and purchase consequences of customer participation in small group brand communities. International Journal of Research in Marketing, 2006. 23 (1): p. 45-61.

[4] Barabasi, A. L. and R. Albert, Albert, R.: Emergence of Scaling in Random Networks. Science 286, 509-512. Science, 1999. 286 (5439): p. 509-12.

[5] Berge, C., Graphs and hypergraphs. 1973: North-Holland Pub. Co.;. 1307-1315.

[6] Bretto, A. and L. Gillibert. Hypergraph-Based image representation. in Iapr International Conference on Graph-Based Representations in Pattern Recognition. 2005.

[7] Bulte, C. V. D. and Y. V. Joshi, New Product Diffusion with Influentials and Imitators. Marketing Science, 2007. 26 (3): p. 400-421.

[8] Chung, M., Study of impact on motives of participation and recognition of brand community over brand loyalty-an example of Fan page of Facebook.

[9] DJ, W. and S. SH. Collectivedynamics of 'small-world' networks. in Nature. 1998.

[10] Dong, J. Q. and W. Wu, Business value of social media technologies: Evidence from online user innovation communities. Journal of Strategic Information Systems, 2015. 24 (2): p. 113-127.
[11] Estrada, E., Introduction to Complex Networks: Structure and Dynamics. 2015: Springer International Publishing. 93-131.

[12] Gale, B. T. and R. C. Wood, Managing Customer Value: Creating Quality and Service That Customers Can See. 1994: Free Press, Maxwell Macmillan Canada, Maxwell Macmillan International. 83-84.

[13] Gallos, L. K., et al., Tolerance of scale-free networks: from friendly to intentional attack strategies. Physica A Statistical Mechanics \& Its Applications, 2004. 344 (3-4): p. 504-509.

[14] Ha, J. W., et al. Layered hypernetwork models for cross-modal associative text and image keyword generation in multimodal information retrieval. in Pacific Rim International Conference on Trends in Artificial Intelligence. 2010.

[15] Heo, M. O., M. Kang, and B. T. Zhang, Visual Query Expansion via Incremental Hypernetwork Models of Image and Text. Lecture Notes in Computer Science, 2010. 6230: p. 88-99.

[16] Kamat, S., F. Page, and M. Wooders. Networks and Farsighted Stability. in Econometric Society 2004 North American Winter Meetings. 2004.

[17] Kim, J. K. and B. T. Zhang. Evolving hypernetworks for pattern classification. in Evolutionary Computation, 2007. CEC 2007. IEEE Congress on. 2007.

[18] Liao, X., Z. Li, and Y. Xi, Discovering and Analyzing Methods on User-innovation Knowledge in Virtual Communities Based on Weighted Knowledge Network. Open Cybernetics \& Systemics Journal, 2014. 8 (1): p. 976-983.

[19] Liao, X., Z. Li, and Y. Xi, Modeling and analyzing methods of user-innovation knowledge in enterprise communities based on weighted knowledge network. Systems Engineering-Theory \& Practice, 2016.

[20] Mak, K. T. and A. Ramaprasad, Knowledge Supply Network. Journal of the Operational Research Society, 2003. 54 (2): p. 175-183.

[21] Mcalexander, J. H. and H. F. Koenig, Building Brand Community. Journal of Marketing, 2002. 66 (1): p. págs. 38-54.

[22] Mcgraw, P. N. and M. Menzinger, Clustering and the synchronization of oscillator networks. Physical Review E Statistical Nonlinear \& Soft Matter Physics, 2005. 72 (2): p. 19-42.

[23] Motter, A. E., C. Zhou, and J. Kurths, Enhancing complex-network synchronization. Physics, 2004. 22 (s 13-14): p. $1820-1825$.

[24] Muniz, A. M. and T. C. O'Guinn, Brand Community. Journal of Consumer Research, 1998. 27 (4): p. 412-32.

[25] Nagurney, A., Supernetworks: An introduction to the concept and its applications with a specific focus on knowledge supernetworks. Organization Collection, 2005. 4.

[26] Nagurney, A. and J. Dong, Supernetworks: Decision-Making for the Information Age. 2002. 76 (2): p. 93-95.

[27] Nambisan, S., Complementary Product Integration by High-Technology New Ventures: The Role of Initial Technology Strategy. Management Science, 2002. 48 (3): p. 382-398.

[28] Parmentier, G. and V. Mangematin, Orchestrating innovation with user communities in the creative industries $\vec{\sim}$. Technological Forecasting \& Social Change, 2013. 83 (2): p. 40-53. 
[29] Ravald, A. and C. Grönroos, The value concept and relationship marketing. European Journal of Marketing, 1996. 30 (2): p. 19-30.

[30] Rheingold, H., The Virtual Community: Homesteading on the Electronic Frontier. 2000: HarperTrade. 1114.

[31] Seufert, A., G. V. Krogh, and A. Bach, Towards knowledge networking. Journal of Knowledge Management, 1999. 3 (3): p. 180-190.

[32] Strogatz, S., Thestructure and function of complexnetworks. 2003.

[33] Thurner, S., 2002): "Statistical mechanics of complex networks. Review of Modern Physics, 2001.74 (1): p. xii.

[34] Valck, K. D., G. H. V. Bruggen, and B. Wierenga, Virtual communities: A marketing perspective $\boldsymbol{\psi}^{3}$. Decision Support Systems, 2009. 47 (3): p. 185-203.

[35] Volpentesta, A. P., Hypernetworks in a directed hypergraph. European Journal of Operational Research, 2008. 188 (2): p. 390-405.

[36] Woodruff, R. B., Customer Value: The Next Source for Competitive Advantage. Journal of the Academy of Marketing Science, 1997. 25 (2): p. 139-153.

[37] Yan, E., et al., Topics in dynamic research communities: An exploratory study for the field of information retrieval. Journal of Informetrics, 2012. 6 (1): p. 140-153.

[38] Yan, S. R., et al., A graph-based comprehensive reputation model: Exploiting the social context of opinions to enhance trust in social commerce. Information Sciences, 2015. 318: p. $51-72$.

[39] Yang, G. and X. Li, The Analysis of Model and Robustness of Regional Logistics Network Based on the Weighted Super-Network. 2009.

[40] Yang, W. W. and X. Liu, The Empirical Research into the effect of the Value of Virtual Brand Community on Brand Loyalty. Systems Engineering, 2010. 28 (3): p. 53-58.

[41] Yun-Jiang, X. I. and Y. Z. Dang, The Discovery and Representation Methods of Expert Domain Knowledge Based On Knowledge Network. Systems Engineering, 2005. 23 (8): p. 110-115.

[42] Yun-Jiang, X. I. and Y. Z. Dang, Method to Analyze Robustness of Knowledge Network based on Weighted Supernetwork Model and Its Application. Systems Engineering - Theory \& Practice, 2007. 27 (27): p. 134-140.

[43] Yun-Jiang, X. I. and Y. Z. Dang, The Method to Analyze the Robustness of Knowledge Network based on the Weighted Supernetwork Model and Its Application. Systems Engineering-Theory \& Practice, 2007. 27 (4): p. 134-140. 